\title{
Recent trends in hospital use by children in England
}

\author{
R MacFaul, U Werneke
}

\begin{abstract}
Background-Routine hospital statistics for England appear to overestimate use of children's wards and include numbers of well newborn babies staying with their mothers after delivery ("well babies").

Aim-To review trends in use of children's wards excluding data on newborn babies. Methods-We reviewed routine, published, and age stratified data requested from the Department of Health to identify separately "well babies" and babies receiving neonatal specialist care from admissions (surgical and paediatric) to children's wards.
\end{abstract}

Results-Routine reports for paediatric activity contain large numbers of "well babies", (almost half the total) as well as babies receiving specialist neonatal care. After excluding these, paediatric admissions represent $9.9 \%$ of the child population aged under 5 years each year (an additional $2.5 \%$ are admitted for surgical care). Between 1989 and 1997 paediatric admissions rose by $19 \%$ and surgical admissions fell by $25 \%$ with a plateau reached in overall child admissions. There are now fewer beds in which children stay for a shorter time and there is more day case surgery. Neonatal specialist care work has risen despite a fall in births.

Conclusion-Categories should be established for reporting paediatric episodes on children's wards separately from those on neonatal units, with better identification of "well babies". When monitoring use of children's inpatient facilities or planning new units, care must be taken to separate paediatric data on neonatal units from work on children's wards. Children's surgical episodes should also be taken into account.

(Arch Dis Child 2001;85:203-207)

Keywords: admissions; utilisation; hospital use; hospital statistics

Department,

Pinderfields Hospital, Wakefield WF1 4DG,

UK

R MacFaul

Maudsley Hospital, Denmark Hill, London SE, UK

U Werneke

Correspondence to: Dr MacFaul

mfrod@easynet.co.uk

Accepted 14 May 2001 rics" to refer only to medical care to distinguish it from children's surgical care). In contrast to data presented for adult hospital inpatient use, mainly reporting admissions from outside hospital, statistics used for paediatrics include large numbers of "well babies". These are babies born in hospital, so accompany their mothers on postnatal wards; most are "well" and receive only a brief screening examination from the paediatric team. More specialist paediatric work takes place with a minority of newborn babies admitted to special care unit cots, though special care is provided for others on postnatal wards. Many more children are admitted from home to children's wards for paediatric specialist care. In routine NHS hospital episode statistics (HES), "episodes" are largely equivalent to admissions with the result that most newborn baby stays, including "well babies", are allocated to the specialty of paediatrics in an equivalent way to inpatient stays allocated in adult specialities. More desirably, they would be categorised separately as neonatal or well baby stays. Summary statistics, derived from different sources used for monitoring current paediatric performance and planning are presented in a similar way as those for adult specialties and are thus open to misinterpretation.

In our view, it is important that the two major components of inpatient paediatric work - newborn care and work on children's wards - are identified and separately evaluated. In this paper we aim to identify work on children's wards separately from newborn work and to show trends in this workload which have occurred over the past 10 years. We also give some consideration to children's surgical work.

\section{Methods}

We reviewed and compared available data for England focusing on the past seven years by using NHS sources for the following: births, child population, hospital episode statistics, the hospital inpatient enquiry (up to 1985), and health service indicators. We also refer to data summarised in a recent publication, Birth counts. ${ }^{2}$ At our request, the statistics division of the Department of Health has categorised hospital episode statistics by age of admission in the first month. We also reviewed data published by the Office of Health Economics ${ }^{3}$ and (unpublished) utilisation data collated in 1999 for the National Beds Inquiry. ${ }^{4}$ In presenting the results we acknowledge the differences between episodes and admissions (each episode representing a different stage of care or of consultant involvement). In paediatrics, although some patients will have two or more episodes during one admission, the number has been shown to be very small as a proportion of the total although it can be a larger factor in newborn special care. 
Table 1 Annual births for England

\begin{tabular}{ll}
\hline Year & All births \\
\hline 1988 & 657551 \\
1989 & 652413 \\
1990 & 669988 \\
1991 & 663878 \\
1992 & 654765 \\
1993 & 640094 \\
1994 & 632539 \\
1995 & 616663 \\
1996 & 617529 \\
1997 & 610466 \\
\hline
\end{tabular}

\section{Results}

BIRTHS

Despite an overall decline in birth numbers, special and intensive care utilisation increased over the period (tables 1 and 2) with an increase both in babies admitted to special care and the proportion of births receiving these levels of care. Bed days used in neonatal specialist care rose by $43 \%$ over seven years from 1989/90.

HOSPITAL EPISODE STATISTICS (HES)

Table 3 shows hospital episode statistics for paediatrics categorised by age on admission. Examination of the total recorded episodes shows the extent to which episodes in babies aged less than 1 day are included in paediatric activity statistics. This amounted to $57 \%$ in $1991 / 92$ and $50.6 \%$ in $1997 / 98$. Those admitted when aged less than 1 day include "well babies", babies attended by paediatricians on the postnatal wards, and babies receiving special or intensive care. Some episodes in babies aged up to 6 days may be for those admitted to hospital children's wards from home. However, we believe most are babies admitted to special care units from postnatal wards.

Table 2 Bed days for special and intensive care based on data from birth counts ${ }^{2}$

\begin{tabular}{|c|c|c|c|c|c|c|c|c|c|}
\hline \multicolumn{4}{|l|}{ Episodes } & \multicolumn{4}{|c|}{$\begin{array}{l}\text { Bed days and mean length of stay } \\
\text { (LOS) }\end{array}$} & \multicolumn{2}{|c|}{$\begin{array}{l}\text { Activity in } \\
\% \text { births }\end{array}$} \\
\hline Year & $\begin{array}{l}\text { Special } \\
\text { care (SC) }\end{array}$ & $\begin{array}{l}\text { Intensive } \\
\text { care (IC) }\end{array}$ & $\begin{array}{l}\text { All } S C \\
\text { and } I C\end{array}$ & $\begin{array}{l}\text { LOS } \\
S C\end{array}$ & $\begin{array}{l}\text { LOS } \\
\text { IC }\end{array}$ & $\begin{array}{l}\operatorname{LOS} \\
\text { all }\end{array}$ & Bed days & $S C$ & $I C$ \\
\hline $1989 / 90$ & 53592 & 7151 & 60743 & 8.6 & 17.5 & 9.6 & 586034 & 8.3 & 1.1 \\
\hline $1990 / 91$ & 67443 & 8102 & 75545 & 7.7 & 16.7 & 8.7 & 654615 & 10.1 & 1.2 \\
\hline $1991 / 92$ & 67278 & 10023 & 77301 & 8.2 & 17.2 & 9.4 & 724075 & 10.2 & 1.5 \\
\hline $1992 / 93$ & 64257 & 10761 & 75018 & 8.6 & 18.3 & 10 & 749537 & 9.9 & 1.7 \\
\hline $1993 / 94$ & 70224 & 13083 & 83307 & 8.3 & 18.4 & 9.9 & 823586 & 11.0 & 2.1 \\
\hline $1994 / 95$ & 65695 & 14534 & 80229 & 8.8 & 19.0 & 10.6 & 854262 & 10.4 & 2.3 \\
\hline $1995 / 96$ & 58683 & 17053 & 75736 & 9.0 & 18.4 & 11.1 & 841922 & 9.6 & 2.8 \\
\hline
\end{tabular}

Table 3 Paediatric admissions (in 1000s) by age

\begin{tabular}{lcclll}
\hline \multicolumn{7}{c}{ Hospital episode statistics } \\
\cline { 2 - 5 } Year & All paediatrics & $\begin{array}{l}\text { Less than age } \\
\text { 1 day }\end{array}$ & $\begin{array}{l}\text { Age } \\
1-6 \text { days }\end{array}$ & $\begin{array}{l}\text { Age } \\
7-27 \text { days }\end{array}$ & $\begin{array}{l}\text { Over age 28 } \\
\text { days up to 14 y }\end{array}$ \\
\hline $1989 / 90$ & 921 & & & & 376 \\
$1990 / 91$ & 973 & & & & 372 \\
$1991 / 92$ & 978 & 566.9 & 24.1 & 19.1 & 385 \\
$1992 / 93$ & 969 & 569.8 & 24.5 & 19.4 & 391 \\
$1993 / 94$ & 1000 & 570.8 & 26.1 & 20.3 & 416 \\
$1995 / 96$ & 993 & 519.3 & 27.3 & 22.1 & 445 \\
$1996 / 97$ & 983 & 503.1 & 27.1 & 22.7 & 440 \\
$1997 / 98$ & 935 & 473.4 & 26.8 & 22.9 & 447 \\
\hline
\end{tabular}

Data for 1994/95 missing.

Child surgical admissions excluded.

Sum of data in columns 3-6 slightly exceeds column 2 because provided after later analysis by Department of Health statistics division.
WELL BABIES

The extent to which "well babies" are allocated to paediatric workload data is evident from tables 2 and 3, using 1995/96 as an exemplar year. In that year HES reported 519000 babies admitted as a paediatric episode at age less than 1 day, representing $84 \%$ of the 616663 births for that year. In contrast, special and intensive care episodes amounted only to 75736 (12.3\% of births - in our view probably a small overestimate as a baby receiving intensive care is also likely to be logged also as one receiving special care, thus having two episodes allocated during one hospital stay). Not all births have been allocated to paediatrics as "well babies". This could be because they have been logged as receiving special or intensive care, though it could also represent variation in recording practice between hospitals.

\section{BED DAYS}

We calculated bed days used by multiplying the number of episodes by their average length of stay. Bed days used by "well babies" were not calculated. We separately calculated bed days used for special/intensive care from those used on children's wards for paediatric care. Summary HES data from 1998/99 show only $42 \%$ of paediatric episodes as emergencies, and the reported numbers are so large that they must include "well babies" episodes. ${ }^{5}$ Clinical experience and health service indicators in the past confirm that the majority of paediatric admissions to children's wards are emergencies. To estimate paediatric bed days used on children's wards and to exclude data on newborn work (both "well babies" and special/ intensive care), we used length of stay for emergencies only when calculating the total paediatric bed days used on children's wards. Table 4 shows the difference between average length of stay (LOS) reported in HES for all paediatric episodes and for emergencies only. A small underestimate of bed days used on children's wards will arise from this approach, because some newborn admissions to special/ intensive care will be recorded as emergencies, though overall numbers are relatively small. Furthermore, a small proportion of paediatric admissions to children's wards are not emergencies. We calculated bed days for special and intensive care episodes by adding intensive care episode bed days to those calculated for special care episodes to avoid double counting (table 5). Comparing paediatric emergency bed days on children's wards with special and intensive

Table 4 Paediatric length of stay (LOS) by admission category (data from hospital episode statistics)

\begin{tabular}{lll}
\hline Year & $\begin{array}{l}\text { Mean LOS for total } \\
\text { in days }\end{array}$ & $\begin{array}{l}\text { Mean LOS for } \\
\text { emergency episodes }\end{array}$ \\
\hline $1989 / 90$ & 3.9 & 3.0 \\
$1990 / 91$ & 3.7 & 2.9 \\
$1991 / 92$ & 3.5 & 2.7 \\
$1992 / 93$ & 3.4 & 2.6 \\
$1993 / 94$ & 3.2 & 2.4 \\
$1994 / 95$ & 3.1 & 2.3 \\
$1995 / 96$ & 3.1 & 2.2 \\
$1996 / 97$ & 3.0 & 2.1 \\
$1997 / 98$ & 2.8 & 2.0 \\
\hline
\end{tabular}

Child surgical admissions excluded. 
Table 5 Bed days calculated to compare children's ward work with special/intensive newborn care

\begin{tabular}{llll}
\hline Year & $\begin{array}{l}\text { Total paediatric bed days: children's } \\
\text { ward }\end{array}$ & $\begin{array}{l}\text { \% bed days on child special E intensive care } \\
\text { ward }\end{array}$ & $\begin{array}{l}\text { \% bed days for } \\
\text { newborn special } \mathbb{E} \\
\text { intensive care }\end{array}$ \\
\hline $1991 / 92$ & 1827075 & $60.4 \%$ & $39.6 \%$ \\
$1992 / 93$ & 1812537 & $58.6 \%$ & $41.4 \%$ \\
$1993 / 94$ & 1866586 & $55.9 \%$ & $44.1 \%$ \\
$1994 / 95$ & 1868262 & $54.3 \%$ & $45.7 \%$ \\
$1995 / 96$ & 1831922 & $54.0 \%$ & $46.0 \%$ \\
\hline
\end{tabular}

${ }^{\star}$ Child surgical admissions excluded.

${ }^{\star}$ Calculated from mean length of stay of emergency admissisons.

care bed days shows the significant contribution to the totality of paediatric bed days which come from the longer special/intensive stays and thus the potential scale of effect by increasing reported average length of stay for paediatrics. If data from children's ward paediatric episodes are used together with those from special and intensive care to calculate summary statistics and are then interpreted, errors would arise in cost allocation, estimation of children's beds needed, or demand on acute services. The error would be compounded further if data on "well babies" were also included.

CHILDREN'S SURGERY

This is the work arising from the range of surgical specialties treating children (general; orthopaedics; ophthalmic; plastic; ear, nose, and throat, etc) as well as from paediatric surgery. In table 6 , we show LOS for paediatric surgery separately from the other surgical specialties treating children. The surgical data can be regarded as more reliable than paediatric data because distortion through counting "well babies" does not apply.

TRENDS IN CHILDREN'S ADMISSIONS

Figure 1 shows trends over the past nine years for all children admitted to children's wards. For paediatrics, we have only used episodes in babies aged over 6 days. This may slightly undercount the few paediatric admissions from home to children's wards at this age. A general fall in children's surgical episodes has been accompanied by an $82 \%$ rise in day case work (from 81879 elective surgical day cases in 1989 to 149121 in 1997/98). For paediatric medicine, there has been a $26 \%$ rise in inpatient episodes between 1989 and 1997 overall, but from about 1993 this appears to have reached a plateau. Both mean and median LOS have continued to fall over this time, reflecting the skewed distribution consequent on the trend to very short episodes. This

Table 6 Mean length of stay (in days) for children's surgery

\begin{tabular}{lll}
\hline & $\begin{array}{l}\text { Paediatric } \\
\text { surgery }\end{array}$ & $\begin{array}{l}\text { All other surgical } \\
\text { specialties treating } \\
\text { children }\end{array}$ \\
\hline $1989 / 90$ & 3.4 & 3.9 \\
$1990 / 91$ & 3.2 & 3.7 \\
$1991 / 92$ & 2.9 & 4.0 \\
$1992 / 93$ & 2.5 & 3.8 \\
$1993 / 94$ & 2.5 & 3.8 \\
$1994 / 95$ & 2.3 & 3.7 \\
$1995 / 96$ & 2.3 & 3.6 \\
$1996 / 97$ & 1.7 & 3.0 \\
$1997 / 98$ & 1.8 & 2.9 \\
\hline
\end{tabular}

Table 7 Length of stay (LOS) in days, reported in paediatrics report of House of Commons select committee ${ }^{16}$

\begin{tabular}{lll}
\hline Year & Mean LOS & Median LOS \\
\hline $1990 / 91$ & 4.0 & 2 \\
$1991 / 92$ & 3.9 & 2 \\
$1992 / 93$ & 3.8 & 2 \\
$1993 / 94$ & 3.6 & 2 \\
$1994 / 95$ & 3.5 & 1 \\
$1995 / 96$ & 2.3 & 1 \\
\hline
\end{tabular}

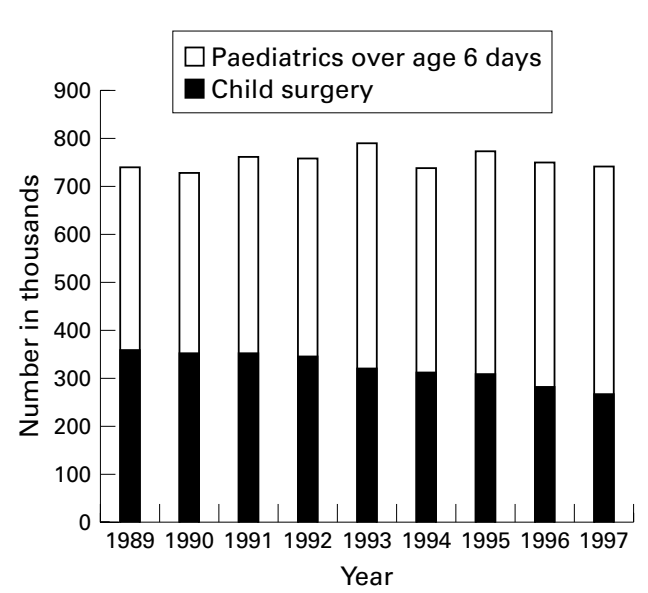

Figure 1 Children's ward admissions-paediatric age over 6 days and children's surgical.

supports the value of reporting median as well as mean LOS (tables 4 and 7).

UTILISATION SUMMARY DATA

Utilisation is reported as episodes per thousand child population per annum. Health service indicators aimed to show admission rates for paediatrics for children aged $0-14$ years. We have reworked this using our paediatric episodes data, including only episodes aged over 6 days, to show that health service indicators probably included some element of newborn work (table 8). Another unpublished source of utilisation data was an analysis carried out for the National Beds Inquiry in 1999. ${ }^{4}$ This excluded paediatric admissions aged under 29 days in an attempt to adjust for newborn work (table 9). This shows much higher utilisation for paediatrics by children under age 5 years rising from 84.9 per thousand child population in 1990 to 99.6 per thousand in 1995 . For the age group 5-14 years, rates rose from 17.4 per thousand in 1990 to 21.6 per thousand in 1995.

Table 8 Episodes per 1000 child population-utilisation from health service indicators (HSI) compared with our calculation of episode rate, excluding newborn episodes

\begin{tabular}{llll}
\hline & $\begin{array}{l}\text { HSI: paediatric } \\
\text { admission rates for } \\
\text { children aged } \\
\text { 0-14 years }\end{array}$ & $\begin{array}{l}\text { Child } \\
\text { population } \\
\text { (in millions) }\end{array}$ & $\begin{array}{l}\text { Paediatric } \\
\text { episode rate over } \\
\text { age 6 days }\end{array}$ \\
\hline Year & 50.2 & & \\
1989 & 48.2 & 9.8 & 41.2 \\
1991 & 47.3 & 9.94 & 41.3 \\
1992 & 50.5 & 10.03 & 43.5 \\
1994 & 51.5 & 10.07 & 46.4 \\
1995 & N/A & 10.06 & 46 \\
1996 & N/A & 10.07 & 46.7 \\
1997 & N/A & \\
\hline
\end{tabular}

${ }^{\star}$ Child surgical admissions excluded. 
Table 9 Utilisation and mean length of stay (LOS) for paediatric inpatient services per 1000 child population

\begin{tabular}{|c|c|c|c|c|}
\hline \multirow[b]{2}{*}{ Year } & \multicolumn{2}{|c|}{ Rate/1000 } & \multicolumn{2}{|c|}{ LOS (days) } \\
\hline & Age $0-4$ & Age 5-14 & Age 0-4 & Age 5-14 \\
\hline 1970 & 37.2 & 7.8 & 7.8 & 9.4 \\
\hline 1973 & 45.4 & 9.5 & 7.1 & 7.8 \\
\hline 1975 & 49.9 & 10.6 & 6.8 & 7.5 \\
\hline 1978 & 56.4 & 11.4 & 5.4 & 5.9 \\
\hline 1980 & 61.4 & N/A & 4.8 & 5.1 \\
\hline 1983 & 70.2 & N/A & 4.0 & 5.2 \\
\hline 1985 & 81.4 & N/A & 3.6 & 4.5 \\
\hline 1989 & 86.9 & 17.7 & 2.9 & 3.1 \\
\hline 1990 & 84.9 & 17.4 & 2.7 & 2.9 \\
\hline 1991 & 86.1 & 17.9 & 2.6 & 2.8 \\
\hline 1992 & 86.3 & 18.2 & 2.4 & 2.8 \\
\hline 1993 & 91.8 & 19.3 & 2.3 & 2.5 \\
\hline 1994 & 92.7 & 19.6 & 2.2 & 2.4 \\
\hline 1995 & 98.1 & 21.0 & 2.1 & 2.2 \\
\hline 1996 & 98.9 & 20.5 & 2.0 & 2.2 \\
\hline 1997 & 99.6 & 21.6 & 1.9 & 2.1 \\
\hline
\end{tabular}

Based on rates up to 1985 from HIPE and from 1989 on spells (HES) (source: Department of Health, 1999).

Admissions aged under 29 days excluded. Calculated on age specific population data. Child surgical admissions excluded.

Table 10 Comparison of numbers of paediatric episodes (in thousands) reported in hospital episode statistice (HES) compared with reports which include paediatric and surgical admissions from Office of Health Economics $(O H E)$ and self reported in general household survey (GHS)

\begin{tabular}{lccc}
\hline Age & $\begin{array}{l}\text { HES } \\
\text { (all paediatric) }\end{array}$ & OHE & GHS \\
\hline $1989 / 90$ & 921 & & \\
$1990 / 91$ & 973 & 1286 & 712 \\
$1991 / 92$ & 978 & 1288 & 777 \\
$1992 / 93$ & 969 & 1435 & 754 \\
$1993 / 94$ & 1000 & 1407 & 666 \\
$1995 / 96$ & 993 & 1432 & 645 \\
$1996 / 97$ & 983 & & \\
$1997 / 98$ & 935 & & \\
\hline
\end{tabular}

Child surgical admissions excluded.

OFFICE OF HEALTH ECONOMICS

The Office of Health Economics publishes numbers of paediatric episodes, but numbers reported are so large that these data almost certainly include "well babies" (table 10). This raises questions about how they estimate inpatient costs in their publication.

\section{Discussion}

Children make heavy use of hospitals for paediatric and surgical inpatient care, but reported activity in NHS hospital episodes statistics (HES) for the specialty of paediatrics needs to be interpreted cautiously to avoid over estimating usage. At first sight, the HES data suggest a very high level of hospital utilisation for paediatrics, reporting between 900000 and just over one million episodes each year, with surgical work additional to this. But the paediatric numbers include about 500000 newborns, both "well babies" and babies receiving special or intensive care.

In fact, the work for inpatient children's wards for both children's surgical and paediatric care is of the order of 737000 annual episodes (using 1995 as an example, there were 467000 paediatric episodes and 305000 for surgery). The Compendium of health statistics published by the Office of Health Economics (OHE) also suggests excessively high levels of usage because they appear to include "well babies" in the numbers they report (table 10). ${ }^{3}$
For example for 1995, OHE report 1407000 annual episodes for children. Of these, 1043000 inpatient episodes were for the age group 0-4 years. Based on the child population for that year, this would be equivalent to $32.5 \%$ of the population being admitted to hospital for either paediatric or surgical care. In our view, supported by reports of The General Household Survey (GHS), this is unlikely. OHE reports 364000 episodes in that year for the 6230746 children aged 5-14 years, equivalent to $5.8 \%$ of the child population. In contrast the GHS, ${ }^{6}$ based on self reporting of admissions for children's surgical and medical care, reports only $9 \%$ of the child population age $0-4$ years being admitted in 1995, and $4 \%$ of those aged 5-14 years. High reported admission numbers in HES cannot be explained reasonably by "episode inflation", which means multiple episodes (finished consultant episodes) being counted during one hospital stay. These are lower for child admissions compared to any other age group with a ratio of episodes to hospital stays of less than 1.05 (DoH statistics branch). Furthermore, in 1998/99 episodes exceeded hospital stays by only $3.6 \%$. Neither can they be explained on this large scale by some children being admitted on multiple occasions.

Hospital use by children varies between health authorities. The health service indicators for 1994/95, for example, show variation in paediatric admission rates for those aged 0-15 with a mean of 51.5 per thousand child population (range 27.7 to 127 ) ${ }^{7}$ Eighty-five per cent of admissions were emergencies with an average LOS of 2.6 days. This would equate to about $4-5 \%$ of children aged $0-14$ years being admitted for care by a paediatrician in any given year. These data are more consistent with GHS reports. The health service indicator data do not include children's surgical admissions, but may have included an unknown extent of newborn work.

Over half of all admissions for children are for surgical care. This proportion varies according to age. Taking 1995 as an illustrative year, $24 \%$ of all $0-5$ year old children's admissions were for surgical care compared with $61 \%$ of admissions for those aged $5-15$ years of age. These equate to admission rates of 25.5 per thousand child population aged $0-4$ years and of 33.2 per thousand for age 5-14 years. About half of children's surgical admissions are for emergencies. Trends show children's surgical workload falling slightly with LOS and overnight stays becoming shorter. Simultaneously, day case surgery has increased.

Hospital utilisation varies with social class of the population. In one report, $7.2 \%$ of the most deprived children were admitted to hospital each year for surgical or paediatric care compared with $5.5 \%$ of the most advantaged. ${ }^{8}$ Admission rates for children aged 0-4 years for gastroenteritis in the West Midlands ranged over a five year period from 33.4 per thousand child population for the most affluent to 67 per thousand for the most deprived; similar patterns were seen for respiratory infection 
admissions. ${ }^{9}{ }^{10}$ Other factors influencing hospital utilisation include proximity to hospital, degree of urbanisation, ${ }^{11}$ and different clinical practices in primary and paediatric care resulting in different pathways into hospital, for example after self referral to $A \& E$. In one study, $8.6 \%$ of 2003 child general practitioner acute contacts seen out of hours in six cooperatives were referred for admission. ${ }^{12}$ This contrasts with another study showing that a third of non-trauma child self referrals to A\&E were admitted. ${ }^{13}$

Since 1989 the previously rapid increase in paediatric admissions ${ }^{14}$ has slowed down and length of stay (LOS) continues to decrease (table 5). But even when corrected for the likely overestimates in HES data, utilisation of acute inpatient services is high, especially among younger children. Admissions for inpatient overnight surgical care have decreased (accompanied by increasing trends to day case care).

When planning or reviewing children's inpatient facilities, joint assessment of paediatric medical and surgical bed use is necessary as these are often shared between paediatrics and surgical specialties treating children. Mean LOS is used to compare performance between hospitals on children's wards. It can also be used to determine the number of children's beds required. But it is essential that paediatric statistics relating to children's wards only are used when evaluating data on LOS for calculating children's ward bed requirements. ${ }^{15}$ Special or intensive neonatal care data need to be excluded because an artificially high LOS would result from the effect of the much longer stays and resulting bed days. This is particularly so because of rise in bed days occupied in neonatal special and intensive care units. Care must also be taken to exclude data on "well babies". Excluding this newborn data may also reduce the skew of the distribution, making mean LOS a more valid measure.

The number of children's beds is decreasing. In 1990/91, there were 10009 (1.05 per thousand child population) and in 1995/96, 8868 beds (0.89 per thousand) - an $11.4 \%$ decrease. ${ }^{16}$ The rise in paediatric admissions has been accommodated by reducing LOS and more day case surgery. However the skew towards admission of younger children, many of whom need cubicle accommodation to control infection, has not been accompanied by an increase in the provision of these facilities. Consequently there are likely to be problems during the predictable annual increased demand arising from respiratory and intestinal infections. In future, separate identification of single occupancy cubicles should also form part of any evaluation of need. Attention should be given when designing units to take account both of short stays and new ways in which paediatrics supports primary and $A \& E$ services.

1 NHSE. Welfare of children and young people in hospital. London: HMSO, 1991.

2 Macfarlane A, Mugford M. Birth counts. Statistics of pregnancy and childbirth. London: The Stationary Office, 2000 .

3 Hospital services 37. Office of Health Economics acute in-patient statistics by age group 1980-1995. Compendium of health statistics. London: Office of Health Economics, 1997.

4 Department of Health. Shaping the future NHS: long term planning for hospitals and related services. Consultation planning for hospitals and related services. Consultation
document on the findings of the National Beds Inquiry. Locument on the findings of the Nation

5 Department of Health. Hospital episodes statistics for England, financial years 1989-1999, finished consultant episodes. Blackpool: Department of Health

6 Office for National Statistics. General household survey. London: HMSO (annual publication).

7 Department of Health. Health service indicators (1993/94 to 1996/97). London: Department of Health.

8 Cooper H, Smaje C, Arber S. Use of health services by children and young people according to ethnicity and social class: secondary analysis of a national survey. $B M F$ 1998;317:1047-51.

9 Olowokure B, Hawker J, Weinberg J, Gill N, Sufi F. Deprivation and hospital admission for infectious intestinal diseases. Lancet 1999;353:807-8.

10 Hawker J, Olowokure B, Sufi F, et al. Social inequalities and hospital admission for respiratory infection. In press.

11 Thakker Y, Sheldon TA, Long R, MacFaul R. Paediatric inpatient utilisation in a district general hospital. Arch Dis Child 1994;70:488-92.

12 Rolands M. NHSE Primary Care R\&D Centre. Personal communication, 1997.

13 Armon K, Stephenson TJ, MacFaul R, et al. Determining the common presenting problems to paediatric accident and emergency. Paediatrics Today 1999;7:20.

14 MacFaul R, Glass E J, Jones S. Appropriateness of paediatric admission. Arch Dis Child 1994;71:50-8.

15 MacFaul R, Long R. Major problems with paediatric bed usage statistics. Arch Dis Child 1991;66:504-7.

16 House of Commons Select Committee. Hospital services for children and young people. London: HMSO, 1997. 